\title{
VISIBLE AND HIDDEN RISK FACTORS FOR BANKS
}

\author{
Til Schuermann \\ Kevin J. Stiroh* \\ Federal Reserve Bank of New York \\ 33 Liberty St. \\ New York, NY 10045
}

This Draft: May 2006

This Print: May 24, 2006

Keywords: commercial banks, risk management, portfolio choice, systemic risk. JEL Codes: G12, G21.

\footnotetext{
* Schuermann: Research Officer, Federal Reserve Bank of New York: til.schuermann@ny.frb.org; (212) 7205968. Stiroh: Assistant Vice President, Federal Reserve Bank of New York; kevin.stiroh@ny.frb.org; (212) 7206633. We thank Tobias Adrian, Phil Strahan, Zhenyu Wang, and seminar participants at the Federal Reserve Bank of New York for helpful suggestions, and Sarita Subramanian for excellent research assistance. Any views expressed represent those of the authors only and not necessarily those of the Federal Reserve Bank of New York or the Federal Reserve System.
} 


\begin{abstract}
$\underline{\text { Abstract }}$
This paper examines the common factors that drive the returns of U.S. bank holding companies from 1997 to 2005. We compare a range of market models from a basic one-factor model to a nine-factor model that includes the standard Fama-French factors and additional factors thought to be particularly relevant for banks such as interest and credit variables. We show that the market factor clearly dominates in explaining bank returns, followed by the Fama-French factors. The bank-specific factors are not informative, particularly for the largest banks, which take advantage of protection in the form of interest rate and credit derivatives. Even in our broadest model, however, considerable residual variation remains, with the mean pairwise correlation of residuals for the largest banks near 0.25 . This finding suggests that important hidden factors remain. A principal component analysis shows that this residual variance is relatively diffuse, although the largest banks do tend to load in the same direction on the first component. When compared to the returns of large firms in other sectors, bank returns are relatively well explained with standard risk factors, and both the residual correlation and degree of factor loading agreement are not particularly large. These results have clear implications both for public policymakers seeking to quantify those shared bank exposures that create systemic risk and to portfolio managers seeking to devise optimal diversification strategies.
\end{abstract}




\section{Introduction}

U.S. banks are becoming larger and more complex, and they appear to be better able to withstand business cycle fluctuations (Schuermann (2004)). Nonetheless, there is concern that they are becoming more risky, at least in a systemic sense where financial sector shocks might disrupt the entire financial system and impact the broader macroeconomy. ${ }^{1}$ De Bandt and Hartmann (2002) offer a useful framework for discussing systemic risk and identify two distinct channels - a "narrow" one that reflects contagion as an adverse shock propagates through the system and a "broad” one where shocks simultaneously affect a large number of institutions. ${ }^{2}$

This paper focuses on the broad view of systemic risk by taking careful stock of the common, or systematic, factors that drive risk and return across U.S banks. ${ }^{3}$ The intuition is obvious: if many large banks are holding similar positions, facing the same exposures, or pursuing similar strategies, then the U.S. banking sector as a whole becomes more exposed and broad systemic risk rises. This intuition holds for both visible and hidden factors, so we identify a wide range of observable factors and then quantify the relative importance of the unobservable ones.

The questions of systemic risk and common exposures are clearly of enormous importance for regulators, industry participants and investors, and there is some sentiment that the U.S. financial sector is indeed becoming more vulnerable to systemic risk. Rajan (2005), for example, argues that compensation schemes at many financial firms may induce herding behavior as managers seek insurance against under-performing their peers. This type of common exposure may increase the possibility of a severe tail event, particularly if exacerbated by

\footnotetext{
${ }^{1}$ See BIS (2001), Geithner (2004), and Rajan (2005) for specific discussions.

${ }^{2}$ Kaufman (2000) discusses a similar framework where systemic risk could reflects a large shock that affects the entire system, contagion as shocks propagate, or similar exposures across institutions.
} 
liquidity and informational frictions. Empirically, Houston and Stiroh (2006) show that actual volatility for commercial banks has indeed risen and that this reflects a growing importance of common, industry-level shocks.

Our point of departure is the familiar capital asset pricing model (CAPM), which allows a simple decomposition of total variation of returns (a standard measure of risk) into a common, systematic portion and a firm-specific, idiosyncratic component. We expand this single-factor framework to include a range of additional risk factors, e.g., the familiar Fama-French factors, interest rate, credit risk, liquidity, and overall volatility measures, and then compare significance, explanatory power, stability, and impact on the systematic/idiosyncratic decomposition across the models. Our goal is not to develop an accurate asset pricing model, but rather to make use of existing standard models and evaluate their relative usefulness for commercial banks.

Accurately disentangling systematic and idiosyncratic factors is critical from a variety of perspectives. Correlation of risks has implications for the stability of the financial sector and the macroeconomy via systemic risk concerns, and this necessarily reflects systematic factors because idiosyncratic risk, by definition, is (or ought to be) cross-sectionally independent. This, of course, is true only if we can identify and capture all common factors, so conditional independence may be a distant goal empirically. There are also clear portfolio choice implications as the degree of return correlation has a direct impact on optimal portfolio strategies. Finally, filtering out dependence by conditioning on observable common factors is critical for risk management, especially credit risk management, as most models presume borrower returns to be conditionally independent (Lando (2004, ch. 9)). ${ }^{4}$ Indeed, Das, Duffie, Kapadia and Saita (2006) argue that conditioning on the typical observed factors is not enough to

\footnotetext{
${ }^{3}$ Data are typically for bank holding companies and financial holding companies, and we use the term "bank" throughout for ease of exposition.
} 
explain observed default clustering, and they propose the inclusion of a latent factor via a frailty model.

We examine weekly returns for U.S. banks from 1997 to 2005 and show that the market risk factor clearly dominates in terms of both economic and statistical significance. The single market factor, for example, absorbs between one-quarter to one-half of the total variation in large bank returns. ${ }^{5}$ Including additional risk factors typically generates only a modest gain, and when there are substantial gains it is not from adding interest rate factors thought to be relevant to bank returns, but instead from adding the familiar Fama-French factors, HML and SMB.

These results are strongest for the larger, more sophisticated banks, so one potential explanation is that financial innovation, particularly interest rate and credit derivatives, have allowed banks to successfully hedge out a significant amount of this risk exposure that drove returns in earlier periods. Observed differences between large and small bank risk factor and our interpretation are consistent with the empirical work of Minton et al. (2005) and Purnanandam (2005), who report that large banks are much more active users of credit derivatives and interest rate derivatives, respectively.

Our results also indicate that liquidity risk, as measured by the change in commercial paper spreads, does not impact bank returns adversely. This evidence is consistent with previous studies (Gatev and Strahan (2006) and Gatev, Schuermann and Strahan (2005)), which argue that banks play a special role as "liquidity providers of last resort.” Similarly, aggregate volatility, measured either historically via an EGARCH approach or using an index of implied volatilities, namely the VIX, is relatively unimportant in determining bank returns.

\footnotetext{
${ }^{4} \mathrm{An}$ interesting exception is the contagion model of Giesecke and Weber (2004).

${ }^{5}$ We define a bank as being "large" in a year if it is included in the S\&P 500 index in that year in order to allow a consistent comparison with large firms in other sectors.
} 
Even in our broadest model that includes all nine factors, however, considerable residual correlation remains. For example, the mean pair-wise correlation of residuals from our broadest model is about 0.24 for the largest banks. This is important as it suggests that standard models using observable factors are not adequate for understanding the forces that drive common movements in bank returns. Consequently, there must be some "hidden" or as yet unobserved factors that are also important for explaining bank returns. This opens the possibility of systemic risk through an unobservable channel if many large banks react similarly to a shock to this hidden factor (or factors) and also reduces the potential for effective portfolio diversification, both for investors and for policy makers. ${ }^{6}$ This type of systemic risk from a hidden shock may a bigger concern from a supervisory or risk management perspective as it is intrinsically harder to understand, and forecast, and hedge.

To further investigate these unobserved factors, we perform a principal component analysis on the market model residuals and show that this unexplained variation is relatively diffuse. The first component accounts for about $27 \%$ of the residual variation of the large banks, while it typically takes about four principal components to explain half of that variation. In most years, however, banks generally load in the same direction on the first principal component. This leaves open the possibility that a shock to this unobserved factor would adversely impact a substantial portion of the U.S. banking industry, which complicates supervisory efforts and limits the potential for portfolio diversification of large banks.

To provide some perspective on our results for large banks, we compare the performance of the market model, the relative importance of unobserved factors, and the degree of residual correlation across 10 other sectors using all firms in the S\&P 500 Index from 1997 to 2005. We find some important differences for banks, but all some surprising similarities. Overall, the

\footnotetext{
${ }^{6}$ See BIS (2001) and Nicolo and Kwast (2002) for discussions.
} 
market models do a better job of explaining bank returns, as measured by the average adjusted$R^{2}$, than for other large firms. This likely reflects the increased homogeneity and internal diversification of the largest banks, which now offer many of the same products and operate in the same geographic markets. As a result, these firms are able to shed idiosyncratic risk, but are left with the common systematic risk in the market and Fama-French factors.

Variation and correlation of the market model residuals, which are important from a systemic sense, however, are fairly typical for large banks. The explanatory power of the first principal component in explaining residual variance, for example, is quite similar to most other sectors and far below the Energy and Material sectors, where one omitted factor, presumably oilprice related, drives residual variation. The degree of agreement in the loading direction is somewhat higher than in the typical sector, but not extreme. Finally, the correlation of residuals is substantial, but again not extreme. This likely reflects the relative similarity of large banks when compared against the diversity of firms in other sectors likes Consumer Discretionary or Consumer Staples.

We conclude that while there are important hidden risk factors for U.S. banks, they are not large relative to large firms in other sectors. This assuages some concerns about systemic risk as there does not appear to be a single omitted risk factor for banks, but does leave open the possibility of systemic concerns through the "broad channel" described above. If banks react similarly to unobserved shocks, a large shock could adversely affect many of the largest institutions and impact the broader macroeconomy.

The remainder of the paper proceeds as follows. We lay out the modeling framework, including the factor approach, in Section 2. Section 3 provides a description and summary of the data used in the empirical analysis, which is presented in detail in Section 4. Section 5 compares the results for the banks to firms in other sectors. Section 6 provides some concluding remarks. 


\section{Modeling Framework}

Our strategy for examining the systematic factors that drive bank returns is to begin with a conventional one-factor capital asset pricing model (CAPM) and then add factors that have been used in the banking literature and in the broader finance literature to develop alternative return models. This step-wise process allows us to evaluate the marginal value of these factors by comparing $\bar{R}^{2}$, the heterogeneity across institutions and over time, and the residual correlation from each model. To be sure, our objective is not to develop or build an accurate asset pricing model per se. Rather we take existing models, as defined by the risk factors used, to explain common variation of bank returns using time series regressions.

\subsection{Decomposing Risk}

We begin with a standard return generating process where return for bank $i$ from period $t$ 1 to $t, r_{i, t}$, is assumed to follow a simple factor model:

$$
r_{i, t}=\alpha_{i}+\boldsymbol{\beta}_{i}^{\prime} \mathbf{f}_{t}+\varepsilon_{i, t},
$$

where $\alpha_{i}$ is a possibly non-zero drift for bank $i, \mathbf{f}_{t} \sim\left(\boldsymbol{\mu}_{f}, \Sigma_{f}\right)$ is a vector of factors with mean $\boldsymbol{\mu}_{f}$ and covariance matrix $\sum_{f}, \beta_{i}$ is a vector of factor loadings for bank $i$, and $\varepsilon_{i, t}$ is a purely idiosyncratic shock with variance $\sigma_{i}^{2}$ that is assumed to be uncorrelated across banks. In our application, we consider weekly returns. For early treatments of this type of factor approach, see Ross (1976) and the generalization of Ross’s results by Chamberlain and Rothschild (1983).

Eq. (1) states that any cross-sectional correlation is driven entirely by the systematic factors $\mathbf{f}_{t}$, although firms may have different sensitivities to those factors as expressed through different loadings, $\boldsymbol{\beta}_{i}$. Once that dependence is controlled for, say by including the complete $\mathbf{f}_{t}$ vector in an ordinary least squares (OLS) return regression, the remaining variation due to $\varepsilon_{i, t}$ is 
purely idiosyncratic. In this way, returns are said to be conditionally independent, a crucial assumption in portfolio choice and risk management.

It is useful to separate returns into an expected and an unexpected component, as in

$$
r_{i, t}=\mu_{i}+\xi_{i, t},
$$

and, following Eq. (1), we may write the expected return as

$$
\mu_{i}=\alpha_{i}+\boldsymbol{\beta}_{i}^{\prime} \boldsymbol{\mu}_{f},
$$

and the unexpected component as comprised of the weighted factor innovations and the firm specific innovation, namely

$$
\xi_{i, t}=\boldsymbol{\beta}_{i}^{\prime}\left(\mathbf{f}_{t}-\boldsymbol{\mu}_{f}\right)+\varepsilon_{i, t} .
$$

The total return variance, $\sigma_{\xi, i}^{2}$, combines the contribution from the systematic factors, $\sum_{f}$, with the purely idiosyncratic variance:

$$
\sigma_{\xi, i}^{2}=\boldsymbol{\beta}_{i}^{\prime} \Sigma_{f} \boldsymbol{\beta}_{i}+\sigma_{i}^{2} .
$$

\subsection{Alternative Return Models}

The simplest model of returns is the one-factor CAPM developed by Sharpe (1964) and Lintner (1965):

$$
r_{i, t}=\alpha_{i}+\beta_{m, i} r_{m, t}+\varepsilon_{i, t},
$$

where $r_{m, t}$ is the one-period return of the market factor taken here to be the CRSP value-weighted composite NYSE/AMEX/Nasdaq market return. This model simply states that the only source of systematic, i.e. common, variation affecting bank returns is the market factor. We emphasize that $\beta_{m, i}$ is bank-specific and reflects differences in how each bank loads on the market factor. We refer to this as the "CAPM model."

Demsetz and Strahan (1997) and Stiroh (forthcoming) incorporate three additional interest rate factors thought to be particularly relevant to banks, although they have also been 
used more generally (Petkova and Zhang (2005)). They are the change in the yield, the change in the slope of the term structure, and some measure of the change in the overall credit spreads:

$$
r_{i, t}=\alpha_{i}+\beta_{m, i} r_{m, t}+\beta_{Y, i} \Delta Y I E L D_{t}+\beta_{T M, i} \Delta T E R M_{t}+\beta_{B a a, i} \Delta B a a_{t}+\varepsilon_{i, t},
$$

where $\triangle Y$ YIELD $D_{t}$ is the one-period change of the risk-free rate, proxied by the 3-month Treasury bill, $\triangle T E R M_{t}$ is the one-period change in the slope of the term structure defined as the difference between the 10-year and 3-month Treasury rates, and $\Delta B a a_{t}$ is the one-period change in the option adjusted credit spreads for Moody’s Baa-rated corporate bonds.

We refer to Eq. (7) as the "Bank Factor" model. If these factors are relevant for banks, they should obviously have some statistical significance and increased explanatory power relative to the CAPM in Eq. (6). Moreover, if these factors control for common variation in bank returns, the cross-sectional residuals in Eq. (7) should be less correlated than in Eq. (6).

There is a rich literature in asset pricing that argues for at least two risk factors beyond the overall market return: HML and SMB (Fama and French $(1993,1996)$ ). ${ }^{7}$ HML (high minus low) and SMB (small minus big) are the differences between the returns on diversified portfolios of high and low book to market stocks and small and big stocks, respectively. These two factors are designed to capture the value and firm size effects that have long been documented in the empirical finance literature. ${ }^{8}$ The three-factor "Fama-French" model can be written as

$$
r_{i, t}=\alpha_{i}+\beta_{m, i} r_{m, t}+\beta_{H M L, i} H M L_{t}+\beta_{S M B, i} S M B_{t}+\varepsilon_{i, t} .
$$

Other research has shown that additional factors may be important determinants of returns. Ang, Hodrick, Xing and Zhang (2006) and Adrian and Rosenberg (2006), for example, show that overall market volatility is priced, while Rosenberg and Schuermann (2006) have found factor loading heterogeneity across the credit spectrum. Finally, there is increasing

\footnotetext{
${ }^{7}$ For a recent survey of some of this literature, see Fama and French (2004).
} 
evidence in the literature that liquidity risk is priced. For instance, Amihud (2002) and Pastor and Stambaugh (2003) find that investors require a premium to hold illiquid stocks. Our broadest model, therefore, combines the bank factors and the Fama-French factors with three additional risk factors - market volatility, the Aa credit spread, and commercial paper spreads - in a "Nine-Factor" model:

$$
\begin{aligned}
r_{i, t} & =\alpha_{i}+\beta_{m, i} r_{m, t}+\beta_{H M L, i} H_{M L}+\beta_{S M B, i} S M B_{t}+\beta_{V O L, i} V O L_{t}+\beta_{Y, i} \Delta Y I E L D_{t} \\
& +\beta_{T M, i} \Delta T E R M_{t}+\beta_{\text {Aa }, i} \Delta A a_{t}+\beta_{\text {Baa }, i} \Delta B a a_{t} \beta_{Y, i}+\beta_{C P, i} \Delta C P_{t}+\varepsilon_{i, t}
\end{aligned}
$$

where $\mathrm{VOL}_{t}$ is the one-period overall market volatility, modeled here as an EGARCH(1,1) process of the CRSP value-weighted composite NYSE/AMEX/NASDAQ market return, $r_{m, t}$, $\Delta A a_{t}$ is the change in the option adjusted credit spread for Moody's Aa-rated corporate bonds, and $\Delta C P_{t}$ is the change in the 90-day financial commercial paper spread above the maturity matched Treasury rate.

It is well known that the volatility of market returns is time varying, and the GARCH model has become a benchmark conditional volatility model. The EGARCH (E for exponential) model, proposed by Nelson (1991), also allows volatility to respond asymmetrically to good vs. bad news through a leverage effect. ${ }^{9} \quad$ We also conduct robustness tests using the implied volatility index, VIX. ${ }^{10}$

There is less agreement in the literature on what constitutes a valid metric of liquidity risk. We follow Gatev and Strahan (2006), Gatev, Schuermann and Strahan (2005), and Pennacchi (2006) and use the spread on commercial paper as a measure of market-wide illiquidity especially relevant to banks. Following theoretical work by Kashyap, Rajan and Stein

\footnotetext{
${ }^{8} \mathrm{~A}$ time series of these factors can be easily downloaded from Ken French's website http://mba.tuck.dartmouth.edu/pages/faculty/ken.french/data_library.html

${ }^{9}$ For a recent study comparing volatility models, see Chernov, Ghysels, Gallant and Tauchen (2003).

${ }^{10}$ In each case we scale daily volatilities to weekly by multiplying by $\sqrt{5}$ (there are 5 trading days in the week) and averaging over the number of actual trading days in that week arriving at a weekly volatility estimate.
} 
(2002), banks are said to be in a unique position for providing liquidity insurance by combining open lines of credit and loan commitments to borrowers and transaction accounts to depositors when market-provided liquidity is scarce, i.e., when CP spreads are wide. Many of these open lines of credit serve as backup facilities for issuers of commercial paper.

We do not claim our model or modeling approach to be an exhaustive factor search. Jagannathan and Wang (1996), for example, have shown that the returns on human capital influence stock returns, while Jegadeesh and Titman (1993) and Carhart (1997) identify market momentum as an important factor, at least in the short-run. Rather, our Nine-Factor model is designed to capture factors which are transparent, relatively easy to obtain, and relevant both broadly to all firms (market return and volatility, value and size effects, liquidity) and more narrowly to banks (term structure and credit spreads).

\section{Data and Summary Statistics}

Equity market data are obtained from the University of Chicago’s Center for Research in Security Prices (CRSP) data for all publicly-traded bank holding companies (banks) that operated between 1997 and 2005. We examine this sample because it was a period of relative volatility, which should help identify the various factors, and because it represents the current banking environment in terms of recent financial innovations, regulation, and industry structure. Publicly-traded banks were identified as those institutions that appeared both in the Y-9C regulatory database and in CRSP, where the firms were linked based on the CUSIP-identifier available from Compustat. Equity returns are daily and are adjusted for stock splits and dividend reinvestment by CRSP.

Weekly returns are obtained by cumulating the underlying daily returns. If fewer than 30 weeks of returns in any given year were observed for a given bank, as might happen if that bank was acquired by another, that institution was dropped from the sample for that year only. This 
left between 433 and 520 banks per year, and the return models are estimated separately for each year.

Alternatively, one could use continuous, multi-year time series, when available, for the regressions. Our preference for year-by-year estimates approach is motivated by three factors mergers and acquisitions (M\&As), comparability, and flexibility. Our sample coincides with massive consolidation via M\&A, and it seems unreasonable to treat the most active acquirers, which include many of the largest banks, as a single institution for the full period. As a specific example, the merger between JP Morgan Chase and Bank One was explicitly motivated by a goal of changing firm structure and the underlying risk profile. By estimating separate regressions each year, we are able to include both acquirers and targets as separate entities before a merger, and the merged firm as a separate entity afterward. Second, we are interested in comparing risk factors over bank size and across sectors. To objectively define size classes and allow for an easy comparison with other sectors, we define a as "large" in a given year if it is part of the S\&P 500 index in that year. We can then compare large banks to small, and large banks to other large firms in the S\&P 500. If we had restricted ourselves to a long continuous sample, we would be subject to possibly significant survivorship bias. Finally, year-by-year estimation is also more flexible than a constrained regression that covers the full period. This allows the risk factor loadings to change over time and gives some indication of the evolving relevance of the different risk models.

In Table 1 we show means and standard deviations of weekly bank returns and the number of observations. We split our sample and show results for all banks in the sample, then split between the large and the other banks. Table 2 shows the means and standard deviations of the nine risk factors, i.e., the conditioning variables, for each of the nine years in the sample, as well as over the entire sample period. 
We see a familiar pattern for market returns with high returns in the late 1990s followed by negative returns and increased volatility through 2002. More recently, market returns have become more stable. The average annualized market return is $9.9 \%$ with an annualized standard deviation of $17.8 \%$. For banks, returns are stronger in general and follow the same hump-shaped pattern over time. In particular, 1998, 2000, and 2002 were periods of considerable financial market turbulence and the largest banks showed substantial volatility. ${ }^{11}$ Small banks generally had more stable returns, except in the most recent years.

Credit spread data are option adjusted yield spread (OAS) indices from Merrill Lynch, obtained from Bloomberg. CP spreads are obtained from the Federal Reserve Board H15 data release. Arguably the nonfinancial CP rate is preferred, but this series is plagued with missing data. To be sure, the correlation between the financial and nonfinancial series (for the overlapping dates) is 0.999, so using the former, more complete series seemed sensible. Finally, data for the options implied volatility index VIX is obtained from Bloomberg.

\section{Results}

This section summarizes the estimation results for the four models - CAPM, Bank Factor, Fama-French, and Nine-Factor. Recall that we estimate each model for each bank in our sample using weekly return observations. This amounts to estimating about 16,344 regressions (about $454 \times 9 \times 4$ bank/year/model estimates), so we focus on statistics that describe both the mean and variation of the estimates across models.

\subsection{Comparing Market Models}

In Panel A of Table 3, we present the average adjusted- $\mathrm{R}^{2}, \overline{\mathrm{R}}^{2}$, for the regressions across models for the nine years in our sample for all banks. In each year, the average is taken across

\footnotetext{
${ }^{11}$ See Houston and Stiroh (2006) for a detailed discussion 13 f volatility trends for U.S. financial institutions.
} 
the bank-specific regressions. The last column shows the simple average across those years; thus it is an average (over time) of averages (across banks).

Beginning with the differences across models, we first note that adding the bank factors does not seem to add much explanatory power as average $\overline{\mathrm{R}}^{2}$ increases by only $5 \%$ from 0.112 to 0.117. A more significant improvement in goodness of fit comes from adding the two FamaFrench factors when average $\overline{\mathrm{R}}^{2}$ increases by $24 \%$ to 0.138 . The incremental gain from adding the bank factors as well as volatility and changes in CP and Aa spreads increases average $\overline{\mathrm{R}}^{2}$ just another $3 \%$ to 0.148 . We conclude that market returns are clearly the most important factor for bank returns, followed by the Fama-French factors.

There is considerable variation in the model performances across years. For example, the average $\overline{\mathrm{R}}^{2}$ for all banks in the CAPM ranges from a low of 0.033 in 2000 to a high of 0.170 in 1998. Similar variation is seen in the other models, which shows the sensitivity of this type of exercise to specific market conditions. Comparisons across year show that relative distance across models is also preserved. The one-factor CAPM and the Bank Factor model show just small differences in performance, while the Fama-French model shows a big gain relative to the previous two; the full Nine-Factor model only increases average $\overline{\mathrm{R}}^{2}$ by very little when compared to the Fama-French model, sometimes by less than one percentage point (e.g. in 2000 and 2003; in 1997 and 2001 it is actually a bit lower).

It is well-known that the U.S. banking industry is heavily skewed with a small number of institutions controlling the majority of assets, and there is reason to believe that large banks behave rather differently than small banks. In particular, internal diversification of activities leads equity returns at large banks to be driven largely by systematic factors, while small bank returns are driven more by idiosyncratic factors (Demsetz and Strahan (1997) and Stiroh (forthcoming)). Moreover, differences in the hedging positions, measured by off-balance sheet 
interest rate and credit derivatives (Minton et al (2005) and Purnanandam (2005)), are likely to affect the loadings of each factor differently across the size dimension.

To examine variation in the size dimension, we isolate the largest banks. A bank is considered "large" in a given year if it is part of the S\&P500 index in that year. This decision rule also allows for less arbitrary comparison with large firms in other sectors in Section 5.

The mean $\overline{\mathrm{R}}^{2}$ for the large banks is shown in Panel $\mathrm{B}$ of Table 3, while Panel C gives the mean $\overline{\mathrm{R}}^{2}$ for all other banks. As expected, large bank equity return volatility is dominated by systematic risk - average $\overline{\mathrm{R}}^{2}$ is 0.393 for the one-factor CAPM and 0.457 in the Nine-Factor model - while the volatility of smaller banks is largely idiosyncratic - average $\overline{\mathrm{R}}^{2}$ is around 0.1 in all models. De Nicolo and Kwast (2002) report average $\mathrm{R}^{2} \mathrm{~s}$ for a set of 22 large complex banking organizations in the late 1990s of about 0.50 , up from about 0.30 in the 1980 s.

This is shown more dramatically in Figure 1 where we plot average $\overline{\mathrm{R}}^{2}$ across models and years for the two groups with large banks in the top panel and smaller banks in the bottom panel (drawn to the same scale). Focusing on the larger banks, the model ranking from the total bank sample is largely preserved, although we see substantially more heterogeneity across years. For instance, in 1999 and 2000, although the systematic factors explain less of the total stock return variation than in other years, the additional Fama-French factors are especially important. Indeed the three-factor Fama-French model has a higher average $\overline{\mathrm{R}}^{2}$ than the Nine-Factor model for 2000 and 2001. By contrast, in 2003 there is little distinction between the four models, suggesting that the other eight factors added little to absorb common variation in bank equity returns.

The divergence in explanatory power in 1999 and 2000 reflects the diverging path of bank returns, particularly the largest, from the market as a whole in 1999 and 2000. Table 1, for example, shows that the market posted a mean weekly return of $0.46 \%$ in 1999 , while the largest 
banks posted a modest decline of $0.12 \%$. Fortunes reversed in 2000 with the market entering a period of decline, while banks rebounded with sharply positive returns. This simply reflects the relative strength of the U.S. banking sector during the end of the technology-led bubble in 2000.

While the results for the smaller banks also exhibit considerable variation across time, the pattern is different than for large banks. For instance, average $\overline{\mathrm{R}}^{2}$ is nearly double in 1998 relative to 1997, while large banks showed little change.

Taken together, these results support the assertion that large banks are better diversified internally than are smaller banks. The results also point to significant heterogeneity in both factor sensitivities and importance over time between large and small banks. We do not, however, see any time trend in the relative importance of systematic risk, measured by the explanatory power of our market models, which suggests that market exposures have not been increasing over this period.

\subsection{Residual Correlation}

$\overline{\mathrm{R}}^{2}$ informs on the fraction of the variation explained by a set of factors and should help shed light on the amount of correlation absorbed by conditioning on those factors. In particular, the basic factor model given by Eq. (1) presupposes that the factors account for all of the systematic, i.e., shared variation in returns. As a result, the residuals ought to be uncorrelated. Examining the validity of this assumption is critical because a common component, whether observed and modeled or not, still creates interdependence of bank returns and performance, which in turns affects the possibility of systemic risk and reduces the potential for investor diversification.

To better understand the issue of interdependence, we compute the cross-sectional average correlation of weekly residuals from each model in each year and compare them to the average cross-sectional correlation of the raw, weekly returns. More precisely, we calculate the 
mean pair-wise correlations in each group in each year, i.e., the $1 / 2\left[N_{t} \times\left(N_{t}-1\right)\right]$ correlations for $N_{t}$ banks in year $t$, and take the simple mean. The difference raw return and residual correlations reflects the amount of (linear) dependence accounted for by the factors in the return model. Broadly, a model is preferred if the average correlation of the residuals is lower than for some other model because it indicates that more of the commonality is removed.

In Figure 2 we plot those averages across the eight years in our sample, split by size. The top panel shows the average correlations for large banks and the bottom shows the average for other banks (drawn to the same scale). It is clear that large bank returns are much more correlated than small bank returns, as expected given the regression results in Section 4.1. The mean correlation for large banks, for example, ranged between 0.43 and 0.75 across the sample period, while other banks ranged between 0.07 and 0.17 . Our estimates are quite similar to De Nicolo and Kwast (2002), who report raw return correlations around 0.60 for large banks in the late 1990s.

Idiosyncratic risk clearly dominates for smaller banks, while systematic risk plays a more significant role for the largest banks. This is reasonable as the broader exposure of the large banks ties them more closely to the market as a whole even as internal diversification associated with their scale and scope reduce idiosyncratic risk. In contrast, the smallest institutions are linked more tightly to local market conditions, which appear idiosyncratic on a national scale.

A natural grouping of the models, with the CAPM and Bank Factor model together and the Fama-French and the Nine-Factor model together, is apparent for the largest Banks. That is, adding the three interest rate-related factors to the market factor does very little to absorb crosssectional dependence as the CAPM and Bank Factor model correlations are nearly identical. One needs to add the two Fama-French factors, SMB and HML, to account for additional cross- 
bank dependence. For smaller banks, there is little difference across models, suggesting that the smaller firms load differently on these factors. ${ }^{12}$

Returning to our original question of whether any of these models soaks up the common variation, we conclude that the answer depends on bank size. The mean correlations of residuals for the smaller banks are all around 0.05, often less, making the assumption of conditional independence plausible. This is not the case for the large banks where that average never dips below 0.1 (the minimum of 0.12 occurred in 2003) and is usually above 0.2 for all models. It suggests that a relatively important common factor or factors remains unobserved, even in our broadest model of bank returns. We return to this issue later.

\subsection{Unpacking the Models}

We now turn our attention to the economics of our factor loadings. Questions of obvious importance include: Which particular factors are consistently the most significant? Which are the most economically important? Where is the heterogeneity in factor loadings the largest? Do the loadings shift over time?

The obvious difficulty is the enormity of the number of coefficient estimates, i.e., we estimate approximately 454 bank-level regressions for each of nine years for each of four return models. To summarize these results and assess the statistical and economic significance of a given factor, we view the return regressions as forming a panel with heterogeneous coefficients. Such panels have been studied by Pesaran and Smith (1995) and Pesaran, Smith and Im (1996) who show that instead of considering firm-specific estimates one could examine the means of the estimated coefficients, referred to as the mean group estimates (MGE). This approach assumes that the variations of factor loadings (coefficient estimates) across firms are approximately

\footnotetext{
${ }^{12}$ We also calculated weighted average correlations, using market capitalizations, for the other banks and found
} 
randomly distributed around fixed means. This is the standard random coefficient model introduced into the panel literature by Swamy (1970) and allows us to generate standard measures of statistical significance from the cross-section of parameter estimates.

For example, one would expect that in general (across many, many firms) the market beta in the CAPM model is equal to one, though there is likely to be considerable variation around that expected value. Now, suppose we compute an OLS estimate of the market beta for $N_{t}$ firms in year $t$. Then inference on the MGE, which is the mean across $N_{t}$ estimated betas, can be conducted by computing a standard error of the MGE, much as we would compute a standard error of an estimate of any mean, namely by deflating the empirical standard deviation (in this case measured across $N_{t}$ market beta estimates) by $\sqrt{N_{t}}$. In essence, this is a standard t-test.

In Table 4, we summarize the factor loadings across models by reporting measures of the mean and variation of the estimates. For each factor in each model, we present the mean loading, where the reported value is the average of the MGEs across the nine years in the sample. To indicate the degree of parameter heterogeneity underlying the MGEs, we also report, in parentheses, the proportion of years that the MGE for a given factor was significantly different from zero at the $1 \%$ level, as well as the percentage of coefficients that are negative. Panel A reports the results for the large and Panel B reports for the other banks.

To help interpret the results, consider the basic CAPM results in column 1. The average factor loading on the market factor (this is the typical "market beta") is 1.0546 for the large banks and 0.4321 for the other banks, and the MGE for each sub-sample is significant at the $1 \%$ level or better in nine out of nine years. Thus large banks have significantly more systematic risk than do small banks, as expected. All large banks have a positive loading, while $14 \%$ of the 
small bank estimates are negative. Given our previous discussion, these differences are not surprising as small banks are more likely to be affected by local economic events and idiosyncratic factors, while large banks are more closely tied to aggregate market events.

For large banks, the market factor is the only risk factor that is significant in all years. The market beta is around one and rises slightly across models to 1.2520 in the Nine-Factor model. For the factors thought to be relevant for banks, a drop in short term interest rates ( $\Delta$ Yield) has on average a negative impact on bank returns, although there is substantial heterogeneity as the MGE is significantly different from zero in only five of nine years (BankFactor model) or two of nine years (Nine-Factor model). Moreover, about $40 \%$ of the banks have positive loadings, indicating the presence of natural hedges.

A flattening of the yield curve ( $\Delta$ Term) also has on average a negative impact on large banks in both the Bank Factor and Nine-Factor models, and it is significant in five of nine years in the Bank-factor and just three of nine years in the full Nine-Factor model. Here again there is substantial heterogeneity across banks as about $40 \%$ of them have positive loadings. Credit quality, as measured by changes in the Baa yield spread ( $\Delta$ Baa spread), matters in about half the years: five of nine years in the Bank Factor model and only four years in the Nine-Factor model, albeit with a sign change. Adding changes in yields for high credit quality firms ( $\Delta$ Aa spread), in the Nine-Factor model is significant in five of the nine years for large banks.

The signs on the credit spread variables in the Nine-factor model are also consistent with what we might expect and with results in Rosenberg and Schuermann (2006). Bank lending portfolios are relatively more concentrated toward the middle of the credit spectrum, so a decline in the credit quality of those firms should have an adverse effect on bank returns, i.e., exposure to credit risk is increasing. One reason why the lending portfolio of banks is skewed in this way is due to differential borrower access to capital markets as an alternative source of funding. 
Large corporates, which tend to have better credit ratings, are able to go to the capital markets instead of banks for funding. This alternative is less available to smaller, lower credit quality firms. As the cost of funding increases, i.e., the spread on high credit quality bonds widens, bank loans become more attractive as a capital source.

We find very little evidence of a liquidity risk premium ( $\triangle \mathrm{CP}$ spread) for bank returns. The coefficients are evenly split between positive and negative and they are significant in just three of nine years for the large banks. This is consistent with empirical work by Gatev and Strahan (2006) and Gatev, Schuermann and Strahan (2005), and theoretical work by Kashyap, Rajan and Stein (2002). By combining open lines of credit and loan commitments to borrowers and transaction accounts to depositors, banks are in a unique position to provide liquidity insurance. In this sense, they act as the "liquidity provider of last resort" by promising to offer cash on demand through commercial paper backup lines of credit. Banks also continue to provide liquidity to customers through their role as issuers of transactions deposits. In this way one would not expect investors to require a liquidity premium for holding bank stocks.

By contrast, the Fama-French factors, HML and SMB, are typically statistically significant for the large banks. In the Fama-French model, for example, HML is significant in six of nine years, while SMB is significant in seven years. In the Nine-Factor model, the HML significance is similar (seven of nine years), while SMB drops to four years of significance. As shown earlier in our discussion of the explanatory power across models, these familiar equity market risk factors are consistently more important in explaining time series variation in bank returns than are the interest rate factors. With the spread of interest rate derivatives it may not be surprising that banks are able to successfully hedge out a significant amount of the interest rate risk exposure. 
Finally, a measure of overall market risk in the form of an EGARCH model of volatility is significant in only three years. Although on average the loading is positive, here too we see considerable sign heterogeneity in the factor loadings across banks with $37 \%$ of the loadings are negative. The empirical finance literature has had considerable difficulty in finding a consistent and statistically significant relationship between risk and return. ${ }^{13}$ As a robustness check, we repeat the exercise for the Nine-Factor model using the VIX, an index of implied volatilities, instead of our estimated EGARCH volatilities. While on average the loadings are negative, they are not significant in any year for the large banks. Similar to the EGARCH results, about half of the loadings in any given year are positive and thus our overall conclusions remain unchanged regardless of using the EGARCH or VIX volatilities.

The pattern of loadings is somewhat different for the smaller banks. Interest rate and credit factors are significant more often here, though this may be no surprise as smaller banks are likely less sophisticated users of interest rate derivatives to hedge out their interest rate and credit risk exposure. Minton et al. (2005), for example, report that credit derivatives are heavily concentrated among the very largest banks, while Purnanandam (2005) show that large banks are the predominant users of interest rate derivatives.

The Fama-French factors also play a consistently more important role for smaller banks than large banks as the MGE is always significantly different from zero, and the sign switches for SMB. Somewhat differently from large banks, overall market volatility is significant for half the years. Again, this is reasonable if smaller institutions are less able to effectively hedge this type of risk. Finally, smaller banks also display a similar degree of sign heterogeneity in the factor loadings.

\footnotetext{
${ }^{13}$ See, for example, French, Schwert and Stambaugh (1987) and Harvey (2001), while Ghysels, Santa-Clara and Vlakanov (2005) provide a counter-example.
} 
To better understand these size differences, we test whether the loadings on each factor are statistically indistinguishable across groups. Panel C in Table 4 shows the number of years when the MGE for the large banks is significantly different from the MGE for the other banks at the $1 \%$ level. We do this with a simple t-test in each year.

The average market beta, around 1.0 for large banks and 0.4 for other banks, are significantly different in all years, showing the fundamental differences in return drivers. We get a different picture for the Fama-French factors. The HML loadings in the Fama-French model, for example, are statistically indistinguishable between large and smaller banks in five years in the Fama-French model and six years in the Nine-Factor model. SMB, on the other hand, is always significantly different. Indeed, for the Nine-Factor model the average loading on this factor is negative for large Banks (-0.2534 in Panel A) and positive for smaller ones (0.3438 in Panel B), exactly as expected. Significant differences in interest rate factor loadings are less stable over time.

We draw two main conclusions. First, large banks do not require special risk factors. This can be seen in the general significance of the standard market and Fama-French factor, and the general insignificance of the other interest rate-related factors thought to be relevant for banks. Second, the returns of small banks appear to be partially driven by bank-specific risk factors, particularly the yield curve and credit spreads. This divergence is reasonable if these institutions lack the scale or expertise to successfully leverage modern risk-management tools like interest and credit derivatives.

\subsection{Economic Importance}

We now move beyond statistical significance to judge the economic significance of these factors. That is, which factors meaningfully impact bank returns? This is obviously important 
from an investor's perspective, but also from a policy perspective focused on the potential for disruption of financial system.

To address this question, one needs to consider both the loadings and the volatility of the conditioning variable, so we calculate the average impact of a one standard deviation shock to the risk factor on bank returns. For example, if $\hat{\sigma}_{m, t}$ is the estimated standard deviation of the market return in year $t$, and $\hat{\beta}_{i m, t}$ is the corresponding estimated factor loading for the $i^{\text {th }}$ bank, then the average impact of a change to market returns, $x_{m}$, is computed as

$$
x_{m}=\frac{1}{T} \sum_{t=1}^{T}\left(\frac{1}{N_{t}} \sum_{i=1}^{N_{t}} \hat{\beta}_{i m, t} \hat{\sigma}_{m, t}\right),
$$

where $N_{t}$ is the number of banks in year $t$, and in our sample $T=9$ years.

We summarize the results in Table 5, separately for the large (Panel A) and the other banks (Panel B). These results clearly show that the market factor is the most economically important risk factor. Starting with the large banks in Panel A, the impact of a one standard deviation increase in market returns on bank returns exceeds the impact of a similar shock to the Fama-French factor by about a factor of five and a shock to the bank-specific interest rate factors by a factor of ten. For example, a one standard deviation increase in the weekly market return, about $2.47 \%$ on average for the whole sample period, leads on average to between a 0.0250 (CAPM) to 0.0300 (Nine-Factor model) increase in weekly bank returns for the largest institutions, while a one standard deviation shock to SMB leads to a decline of 0.0057 (FamaFrench model) and 0.0047 (Nine-Factor model).

For the other, smaller banks, the impact of a market shock is only about one-third as large as for the large banks, ranging from 0.0095 (CAPM) to 0.0119 (Nine-Factor model). For these banks, however, the Fama-French factors are relatively more important. The relative impact of a shock to the Fama-French factors to market factor shock is about one to three for the small 
banks, compared to one to five for the largest banks. The bank factors, however, are of similarly small importance, respectively.

\subsection{Hidden Factors in the Residuals}

Our final goal is to develop an understanding of the relative importance of the unobserved risk factors. Recall that even though our broadest Nine-Factor model explains, on average, nearly half of the variation in weekly returns for the large banks and is able to account for more than half of the average cross-sectional correlation of returns (correlation of $57 \%$ in raw returns and $24 \%$ in Nine-Factor model residuals), a significant amount of common variation clearly remains.

Understanding the nature of these hidden factors is important for identifying and managing risks, and we focus on the questions of breadth of the unobserved factors and the

underlying parameter heterogeneity. A single, dominant risk factor that is unobserved, for example, may be more worrisome as it implies a potentially large misspecification of the return model and leaves a greater potential for a single event to drive returns across the industry. In contrast, if residual dependence is diffuse in the sense of reflecting many small factors, it is less likely to generate systemic concerns as a specific combination of shocks would be needed to drive common return movement.

We proceed with a principal component (PC) analysis of the residuals to gain a better understanding of the linear dependence remaining in our residuals. We focus on the broadest, Nine-Factor model and perform a standard PC analysis on the residuals from the large banks in each year. Note that our analysis is limited by the number of weekly observations in which we have data for the full sub-set of large banks and that the maximum number of PCs possible varies 
with the number of large banks in each year (ranging from 31 in 2005 to 36 in 2000, 2002 and 2003). ${ }^{14}$

The results are presented in Table 6 . The first row shows the percent of residual variation explained by the first PC, which accounts for about one third of the residual variation, ranging between $19 \%$ (1997) to $47 \%$ (2000). ${ }^{15}$ The first PC was most powerful in 2000, reflecting the divergence between bank returns and general market returns as the U.S. banking industry continued to prosper even as the dot-com bubble was bursting.

The next three rows show the number of PCs needed to account for $50 \%, 75 \%$, and $95 \%$ of the unexplained variance, respectively. To account for half of the variance between two (2000) and five (1997) PCs are needed, and if one wishes to account for up to 95\% of the remaining variance, between 16 and 21 factors are needed. We conclude that the common variation in the residuals is relatively diffuse across several unobserved factors, suggesting that the largest banks are not collectively sensitive to one major risk factor that is unaccounted for in the return models. This is important as it makes it less likely that unexpected shocks to a single, unobserved factor will have a major impact on bank returns or industry performance.

Given that a single factor does account for about a third of the common residual variation, however, it is useful to examine the variation in how banks may load on that factor. If all the loadings are of the same sign, then return sensitivities to this unobserved factor are in no way off-setting across banks. This will be possible only with sufficient parameter sign heterogeneity. The fifth row in

\footnotetext{
${ }^{14}$ The only year with incomplete data is 2000. That year MetLife joined the sample (in April) when it transformed from mutual to stock ownership.

${ }^{15}$ By contrast, a PC analysis on the raw bank returns reveals that the first factor accounts for about $57 \%$ of the total variance.
} 
Table 6 reports the number of the largest banks (out of the total number of large banks in that year) that load negatively on the first PC. We emphasize that these are loadings on unobserved factors without natural economic interpretations, so it is not the sign per se that matters but the sign heterogeneity.

In seven of the nine years, virtually all banks load in the same direction on the first PC: all are positive in 1999 and 2001; all are negative in 2000, and only one is negative in 1997 and one positive in 2005. In the other years, this is some variation, but the signs are very homogeneous. This does raise some concern. While the residual dependence is not overly concentrated in one single unobserved (and potentially unobservable) risk factor, a shock to that factor would tend to move bank returns in the same direction, raising systemic risk concerns and making risk management more difficult as no natural hedging exists.

\section{Are Banks Different?}

We have examined the visible and hidden risk factors driving the returns of U.S. commercial banks and conclude that bank returns are well explained by standard factors (market and Fama-French), but considerable residual variation and correlation remain with most large banks loading in the same direction. This raises some systemic concerns, but an analysis of commercial banks alone cannot address the question of whether this homogeneity and residual variation is large. That is, are these characteristics unique to commercial banks or typical of other large firms? This is important as it provides some perspective for our results, informs on how much concern the residual variation might warrant, and provides further insight on the question of whether commercial banks need to be treated in a special manner.

To address theses issues, we perform the same analysis for other large firms and compare results across well-defined sectors. The S\&P 500 index is a natural laboratory for this analysis: 
it contains the largest U.S. firms and is categorized into 10 sectors. $^{16}$ One of those is the Financial sector, from which we have already separated out Banks (on average about 34 firms in any given year), leaving other Financials (on average about 40 firms a year). The sector names and average number of firms are shown in Table 7.

We then perform all of the same analysis described above for banks, summarized as follows. We calculate weekly returns and estimate each of the four market models, although we focus our analysis on the broadest Nine-Factor model. We then compare explanatory power and perform the principal component (PC) analysis to examine residual variation, the sign homogeneity of the factor loadings, residual correlations. This obviously generates considerable output and we do not discuss the details; rather, we focus on the key summary statistics to compare our earlier commercial bank results to results for other sectors.

We begin with the average explanatory power of our broadest Nine-Factor model across sectors in Figure 3 and Table $7 .{ }^{17}$ We find that the mean $\overline{\mathrm{R}}^{2}$ of $46 \%$ for large banks (also seen in Table 3) is the largest, followed by $41 \%$ for Financials (non-bank firms like the government sponsored enterprises, investment banks, and insurers). At the other end, Consumer Staples and Health Care show mean $\overline{\mathrm{R}}^{2}$ 's below 20\%, while the median of means $\overline{\mathrm{R}}^{2}$ 's across sectors is 28\%. The relatively high explanatory power of the market model for banks likely reflects the continued evolution of the largest banks. These firms are becoming increasingly diversified, both across product lines and geography (Stiroh (forthcoming) and Morgan and Samolyk (2005)), which reduces the relative importance of idiosyncratic volatility. Moreover, returns over this period were largely driven by common market factor related to specific events like the Russian bond default and LTCM in 1988, the events of September 11, 2001, and the accounting

\footnotetext{
${ }^{16}$ The complete list of S\&P 500 firms was obtained from S\&P.

${ }^{17}$ In all cases, we first average across firms in each sector and then average over years.
} 
scandals in 2002 (Houston and Stiroh (2006)). As a result, bank returns are becoming more tightly linked to systematic factors, and the market models perform better. ${ }^{18}$

We are particularly interested in whether the hidden risk factors, reflected in the common residual variation, are relatively diffuse or concentrated for commercial banks. As discussed above, a diffuse set of risk factors is less of a concern than if most of the variation is driven by a single unobserved factor. To investigate this, we performed the principal component (PC) analysis on the residuals from the Nine-Factor model and compare sector results. The first PC explains about $27 \%$ of the residual variation for the average large bank, compared to $21 \%$ for firms in other sectors (measured by the median across sectors) in column 3. By contrast, the first PC is considerably more important in Energy, where the first PC, presumably an energy-related factor, explains more than half of the residual variation, and in Telecommunication Services (34\%).

Even if a given PC explains the majority of residual variation, the overall impact will depend on the distribution of the signs of the factor loadings. For example, if all firms load in the same directions, there is greater probability of an industry-wide or systemic event, conditional on a shock to the hidden factor. Column 4 of Table 7 presents the degree of sign agreement on the first PC, defined as the percentage of observations with the same sign. Banks have the second most "similar" loadings of all sectors, 93\%, compared with a median agreement of $84 \%$. Only Energy, at $98 \%$, is more similarly exposed to the first PC of the residuals, which, unsurprisingly, is highly correlated (35-40\%) with the growth in the price of crude oil.

The final issue is the degree of return correlation, both in terms of actual returns and market model residuals. This is relevant because it indicates how firm outcomes move together

\footnotetext{
${ }^{18}$ We only report results for the Nine-Factor Model, but the large banks show the highest $\bar{R}^{2}$ using all four of the models.
} 
in particular sectors and sheds light on the degree of systemic concern. Beginning with actual returns in column 5, commercial banks show the highest correlation at 0.57 (unweighted mean of all pair-wise correlations, averaged across years), compared to a median of 0.36 for all sectors. This is not surprising given the high $\overline{\mathrm{R}}^{2}$ and shows that bank returns are relatively easy to explain because, in part, they tend to move together more than in other sectors.

But even with the highest market model $\overline{\mathrm{R}}^{2}$, the average correlation of residuals for banks remains high at 0.24 for both the Fama-French and the Nine-Factor model, double the sector median. For sectors like Energy, where an obvious (observed) factor has been left out, namely the price of oil, the average correlation of residuals is even higher at 0.43 .

The degree of linear dependence accounted for by the market models is shown in column 8 of Table 7 for the Fama-French model, while column 9 shows the incremental reduction provided by the six additional factors in the Nine-Factor model. The market and Fama-French factors in the Fama-French model substantially reduce correlation, accounting for more than half (57\%) of the linear dependence for the typical sector. Banks are quite typical in this regard with a reduction of $57 \%$ also. By contrast, these factors reduce the return correlation by only $24 \%$ in Energy, where an unobserved/omitted factor still drives common returns. At the other end of the spectrum, the correlation for Consumers Discretionary and Consumer Staples firms fall $79 \%$ (78\%) as residuals from the Fama-French model are essentially uncorrelated at only 0.07, reflecting the heterogeneity of this sector which includes firms like Tiffany's and Target.

Looking down that last column shows the minimal improvement from the additional factors in the Nine-Factor model. Those six factors are typically able to account for only a $2 \%$ reduction in correlation above and beyond the Fama-French model. This supports our earlier bank-specific result that the workhorse Fama-French model includes the dominant risk factors and that the additional factors are of marginal importance. 
These results offer a mixed view on the potential for the "broad channel” of systemic risk developed by De Bandt and Hartmann (2002). On one hand, the behavior of bank returns raises some systemic concerns - bank returns appear somewhat more highly correlated, show a tighter link to common market factors, are less driven by idiosyncratic factors, and respond in a more homogeneous fashion to the largest unobserved factor. All of these attributes raise the possibility of industry-wide movements with systemic repercussions. On the other hand, we note that the remaining residual variation is not unduly concentrated in a single hidden factor, which lowers the relative importance of that factor.

\section{Conclusions}

Our analysis of bank returns over the last nine years suggests three specific conclusions. First, the market factor clearly dominates in explaining bank returns. Many interest rate-related factors thought to be relevant for understanding bank returns are informative only at the margin for the smaller banks that beyond the largest, most important group. Second, a significant amount of residual correlation remains even in our broadest model. Third, the largest difference for banks relative to other firms appears to be in the explanatory power of the market model, rather than in the importance of the unobserved risk factor and suggests that standard models are not missing an obvious risk factor for banks.

Returning to our original motivation of understanding the evolving potential for systemic risk, our results have mixed implications. On the optimistic side, we do not find any obvious trend in the degree of systematic risk, measured by the explanatory power of our four market models, which implies that common exposures are not rising. There were increased comovements in specific years such as 1998 and 2002, but no clear trend or this sample. Moreover, return variation for the largest, most systemically important banks is relatively well 
captured by standard factors and the unexplained residual correlation appears diffuse. This is similar to large firms in other sectors.

On the pessimistic side, however, these large banks generally load in the same direction on the first principal component of the residuals. Again, this is typical but does imply that shocks to this unobserved factor may have the potential to simultaneously impact many of the largest U.S. banks in the same fashion, which raises the potential for systemic risk. 


\section{References}

Acharya, Viral and Lasse H. Pedersen, 2004, “Asset Pricing and Liquidity Risk,” Journal of Financial Economics 77:2, 375-410.

Adrian, Tobias and Joshua Rosenberg, 2006, “Stock Returns and Volatility: Pricing the Long Run and Short Run Components of Market Risk," unpublished manuscript, Federal Reserve Bank of New York.

Amihud, Yakov, 2002, "Illiquidity and Stock Returns: Cross-section and Time-series Effects," Journal of Financial Markets 5:1, 31-56.

Ang, Andrew, Robert J. Hodrick, Yuhang Xing, and Xiaoyan Zhang, 2006, "The Cross-Section of Volatility and Expected Returns,” Journal of Finance 61:1, 259-299.

Bank for International Settlements, 2001, Report on Consolidation in the Financial Sector, January 2001.

Carhart, Mark M., 1997, “On Persistence in Mutual Fund Performance,” Journal of Finance, 52:1, 57-82.

Chamberlain, Gary and Michael Rothschild, 1983, “Arbitrage, Factor Structure and MeanVariance Analysis on Large Asset Markets,” Econometrica 51:5, 1281-1304.

Chernov, Mikhail, A., Ronald Gallant, Eric Ghysels and George Tauchen, 2003, “Alternative Models for Stock Price Dynamics,” Journal of Econometrics 116, 225-257.

Das, S.S., D. Duffie, N. Kapadia, and L. Saita, 2006, “Common Failings: How Corporate Defaults are Correlated,” Forthcoming, Journal of Finance.

De Bandt, Olivier and Philipp Hartman, 2002, “Systemic Risk: A Survey,” in eds. Charles A. E. Goodhard and G. Illing, Financial Crisis, Contagion and the Lender of Last Resort: A Book of Readings, January, London, UK: Oxford University Press.

De Nicolo, Gianni and Myron L. Kwast, 2002, "Systemic Risk and Financial Consolidation: Are they Related?” Journal of Banking \& Finance 26, 861-880.

Demsetz, Rebecca S. and Philip E. Strahan, 1997, "Diversification, Size, and Risk at Bank Holding Companies,” Journal of Money, Credit and Banking 29:3, 300-313.

Fama, Eugene F. and Kenneth R. French, 1993, "Common Risk Factors in the Returns of Stocks and Bonds," Journal of Financial Economics 33, 3-56.

Fama, Eugene F. and Kenneth R. French, 1996, "Multifactor Explanations of Asset Pricing Anomolies,” Journal of Finance 51:1, 55-84.

Fama, Eugene F. and Kenneth R. French, 2004, “The Capital Asset Pricing Model: Theory and Evidence,” Journal of Economic Perspectives 18:3, 25-46.

French, Kenneth R., G. William Schwert, and Robert Stambaugh, 1987, "Expected Stock Returns and Volatility,” Journal of Financial Economics 19, 3-30.

Gatev, Evan and Philip E. Strahan, 2006, “Banks Advantage in Hedging Liquidity Risk: Theory and Evidence from the Commercial Paper Market,” Journal of Finance 61:2, 867-892. 
Gatev, Evan, Til Schuermann, and Philip E. Strahan, 2005, “How Do Banks Manage Liquidity Risk? Evidence from the Equity and Deposit Markets in the Fall of 1998”, NBER Working Paper No. 10982, forthcoming in Mark Carey and René Stulz (eds.), Risks of Financial Institutions, Chicago, IL: University of Chicago Press.

Geithner, Timothy F., 2004, "Changes in the Structure of the U.S. Financial System and Implications for Systemic Risk," Remarks before the Conference on Systemic Financial Crises at the Federal Reserve Bank of Chicago, October 1, 2004.

Ghysels, Eric, Pedro Santa-Clara and Ross Valkanov, 2005, “There is a Risk-Return Tradeoff After All,” Journal of Financial Economics 76:3, 509-548.

Giesecke, Kai and Stefan Weber, 2004, “Cyclical Correlations, Credit Contagion and Portfolio Losses,” Journal of Banking \& Finance 28, 3009-3036.

Harvey, Campbell, 2001, “The Specification of Conditional Expectation,” Journal of Empirical Finance 8, 573-637.

Houston, Joel and Kevin J. Stiroh, 2006. “Three Decades of Financial Sector Risk,” Federal Reserve Bank of New York Staff Report \#248, April.

Jagannathan, Ravi and Zhenyu Wang, 1996, "The Conditional CAPM and the Cross-Section of Expected Returns,” Journal of Finance 51:1, 3-53.

Juegadeesh, Narasimhan and Sheridan Titman, 1999, "Returns to Buying Winners and Selling Losers: Implications for Stock Market Efficiency,” Journal of Finance, 48:1, 65-91.

Kashyap, Anil K, Raghuram G. Rajan, and Jeremy C. Stein, 2002, "Banks as Liquidity Providers: An Explanation for the Co-existence of Lending and Deposit-Taking,” Journal of Finance 57:1, 33-74.

Kaufman, George G., 2000, "Banking and Currency Crises and Systemic Risk: Lessons from Recent Events,” Federal Reserve Bank of New York, Economic Perspectives, Third Quarter, 9-28.

Lando, David, 2004, Credit Risk Modeling: Theory and Applications, Princeton, NJ: Princeton University Press.

Lintner, John, 1965, “The Valuation of Risk Assets and the Selection of Risky Investments in Stock Portfolios and Capital Budgets,” Review of Economics and Statistics 47, 221-245.

Minton, Bernadette A., René Stulz, and Rohan Williamson, 2005, "How Much Do Banks Use Credit Derivatives to Reduce Risk?” NBER Working Paper \#11579, August.

Nelson, Daniel, 1992, "Conditional Heteroskedasticity in Asset Returns: A New Approach,” Econometrica 59, 347-370.

Pastor, Lubos and Robert F. Stambaugh, 2003, “Liquidity Risk and Expected Stock Returns,” Journal of Political Economy 111:3, 642-685.

Pennacchi, George. 2006, “Deposit Insurance, Bank Regulation and Financial System Risk,” Journal of Monetary Economics 53, 1-30.

Pesaran, M. Hashem, Ron P. Smith, 1995, “Long-Run Relationships from Dynamic Heterogeneous Panels,” Journal of Econometrics 68, 79-113. 
Pesaran, M. Hashem, Ron P. Smith and Kyung S. Im, 1996, "Dynamic Linear Models for Heterogenous Panels,” in Lazlo Mátyás, and Patrick Sevestre (eds.). The Econometrics of Panel Data. Dordrecht, The Netherlands: Kluwer Academic Publishers.

Petkova, Ralitsa and Lu Zhang, 2005, “Is Value Riskier than Growth?” Journal of Financial Economics 78, 187-202.

Purnanandam, Amiyatosh, 2005, "Interest Rate Risk Management at Commercial Banks: An Empirical Investigation,” Mimeo, Ross School of Business, University of Michigan, May.

Rajan, Raghuram G., 2005, “Has Financial Development Made the World Riskier?” presented at the 2005 Economic Symposium at Jackson Hole, WY, sponsored by the Federal Reserve Bank of Kansas City.

Rosenberg, Joshua and Til Schuermann, 2006, "A General Approach to Integrated Risk Management with Skewed, Fat-tailed Distributions,” Journal of Financial Economics 79:3, 569-614.

Ross, Stephen A., 1976, “The Arbitrage Theory of Capital Asset Pricing,” Journal of Economic Theory 13, 341-360.

Schuermann, Til, 2004, "Why Were Banks Better Off in the 2001 Recession?” Federal Reserve Bank of New York, Current Issues in Economics and Finance 10:1.

Sharpe, William F., 1964, “Capital Asset Prices: A Theory of Market Equilibrium under Conditions of Risk,” Journal of Finance 19, 425-442.

Stiroh, Kevin J., forthcoming, "A Portfolio View of Banking with Interest and Noninterest Activities,” Journal of Money, Credit, and Banking, August 2005.

Stiroh, Kevin J., 2005, “New Evidence on the Determinants of Bank-Specific Risk,” unpublished manuscript, Federal Reserve Bank of New York, August.

Swamy, P.A.V.B., 1970,. "Efficient Inference in a Random Coefficient Regression Model," Econometrica 38, 311-323. 
Table 1: Means and Standard Deviations of Bank Returns

\begin{tabular}{|c|c|c|c|c|c|c|c|c|c|c|c|}
\hline \multicolumn{12}{|c|}{ Bank Returns } \\
\hline & & $\underline{1997}$ & $\underline{1998}$ & $\underline{1999}$ & $\underline{2000}$ & $\underline{2001}$ & $\underline{2002}$ & $\underline{2003}$ & $\underline{2004}$ & $\underline{2005}$ & $\frac{1997 \text { to }}{\underline{2005}}$ \\
\hline \multirow{3}{*}{ All Banks } & $\mu$ & $1.08 \%$ & $0.04 \%$ & $-0.05 \%$ & $0.25 \%$ & $0.67 \%$ & $0.47 \%$ & $0.74 \%$ & $0.37 \%$ & $0.08 \%$ & $0.40 \%$ \\
\hline & $\sigma$ & $3.89 \%$ & $4.68 \%$ & $4.34 \%$ & $4.98 \%$ & $4.33 \%$ & $3.97 \%$ & $3.40 \%$ & $3.09 \%$ & $3.02 \%$ & $4.31 \%$ \\
\hline & $\mathrm{N}$ & 507 & 520 & 519 & 504 & 494 & 481 & 486 & 451 & 433 & 488.33 \\
\hline \multirow{3}{*}{$\begin{array}{l}\text { Large } \\
\text { Banks }\end{array}$} & $\mu$ & $0.93 \%$ & $0.28 \%$ & $-0.12 \%$ & $0.68 \%$ & $0.02 \%$ & $-0.06 \%$ & $0.62 \%$ & $0.24 \%$ & $0.12 \%$ & $0.30 \%$ \\
\hline & $\sigma$ & $4.02 \%$ & $5.23 \%$ & $4.46 \%$ & $6.06 \%$ & $4.39 \%$ & $4.92 \%$ & $3.39 \%$ & $2.48 \%$ & $2.27 \%$ & $4.45 \%$ \\
\hline & $\mathrm{N}$ & 34 & 34 & 35 & 36 & 33 & 36 & 36 & 32 & 31 & 34.11 \\
\hline \multirow{3}{*}{$\begin{array}{l}\text { Other } \\
\text { Banks }\end{array}$} & $\mu$ & $1.09 \%$ & $0.02 \%$ & $-0.05 \%$ & $0.21 \%$ & $0.72 \%$ & $0.51 \%$ & $0.75 \%$ & $0.38 \%$ & $0.08 \%$ & $0.41 \%$ \\
\hline & $\sigma$ & $3.89 \%$ & $4.64 \%$ & $4.33 \%$ & $4.90 \%$ & $4.33 \%$ & $3.89 \%$ & $3.40 \%$ & $3.14 \%$ & $3.08 \%$ & $4.30 \%$ \\
\hline & $\mathrm{N}$ & 473 & 486 & 484 & 468 & 461 & 445 & 450 & 419 & 402 & 454.22 \\
\hline
\end{tabular}

Observations are weekly bank returns. Each value is the cross-sectional mean of the mean or standard deviation of weekly returns for a particular bank. A bank is considered "large" in a given year if it is part of the S\&P 500 index in that year. 
Table 2: Means and Standard Deviations of Conditioning Variables

\begin{tabular}{|c|c|c|c|c|c|c|c|c|c|c|c|}
\hline \multicolumn{12}{|c|}{ Factor Returns } \\
\hline & & 1997 & $\underline{1998}$ & 1999 & $\underline{2000}$ & $\underline{2001}$ & $\underline{2002}$ & $\underline{2003}$ & $\underline{2004}$ & $\underline{2005}$ & $\underline{1997-2005}$ \\
\hline \multirow{2}{*}{ Market } & $\mu$ & $0.54 \%$ & $0.42 \%$ & $0.46 \%$ & $-0.15 \%$ & $-0.20 \%$ & $-0.37 \%$ & $0.57 \%$ & $0.25 \%$ & $0.16 \%$ & $0.19 \%$ \\
\hline & $\sigma$ & $2.08 \%$ & $2.74 \%$ & $2.26 \%$ & $3.03 \%$ & $3.12 \%$ & $3.20 \%$ & $2.14 \%$ & $1.52 \%$ & $1.31 \%$ & $2.47 \%$ \\
\hline \multirow{2}{*}{$\Delta$ Yield } & $\mu$ & 0.0032 & -0.0156 & 0.0129 & 0.0109 & -0.0775 & -0.0109 & -0.0048 & 0.0251 & 0.0331 & -0.0026 \\
\hline & $\sigma$ & 0.0722 & 0.1122 & 0.0997 & 0.1151 & 0.1722 & 0.0596 & 0.0346 & 0.0376 & 0.0549 & 0.0981 \\
\hline \multirow{2}{*}{$\Delta$ Term } & $\mu$ & -0.0162 & -0.0056 & 0.0206 & -0.0356 & 0.0793 & -0.0134 & 0.0107 & -0.0237 & -0.0321 & -0.0017 \\
\hline & $\sigma$ & 0.1111 & 0.1158 & 0.1330 & 0.1388 & 0.1998 & 0.1341 & 0.1401 & 0.1260 & 0.0977 & 0.1386 \\
\hline \multirow{2}{*}{$\begin{array}{l}\Delta \text { Baa } \\
\text { spread }\end{array}$} & $\mu$ & 0.0018 & 0.0156 & -0.0047 & 0.0229 & -0.0122 & 0.0081 & -0.0261 & -0.0038 & 0.0056 & 0.0007 \\
\hline & $\sigma$ & 0.0176 & 0.0742 & 0.0272 & 0.0537 & 0.0707 & 0.1724 & 0.0513 & 0.0231 & 0.0555 & 0.0755 \\
\hline \multirow{2}{*}{$\begin{array}{l}\Delta \text { Aa } \\
\text { spread }\end{array}$} & $\mu$ & 0.0018 & 0.0308 & -0.0278 & 0.0102 & -0.0124 & -0.0010 & -0.0061 & -0.0005 & 0.0036 & -0.0002 \\
\hline & $\sigma$ & 0.0189 & 0.1748 & 0.2018 & 0.0311 & 0.0292 & 0.0529 & 0.0175 & 0.0116 & 0.0174 & 0.0928 \\
\hline \multirow{2}{*}{$\begin{array}{l}\Delta \mathrm{CP} \\
\text { spread }\end{array}$} & $\mu$ & 0.0010 & 0.0031 & 0.0023 & 0.0004 & -0.0147 & 0.0015 & -0.0003 & 0.0010 & 0.0040 & -0.0002 \\
\hline & $\sigma$ & 0.0758 & 0.0971 & 0.1290 & 0.1126 & 0.1134 & 0.0463 & 0.0388 & 0.0337 & 0.0647 & 0.0852 \\
\hline \multirow{2}{*}{ HML } & $\mu$ & 0.0017 & -0.0017 & -0.0054 & 0.0068 & 0.0029 & 0.0022 & 0.0006 & 0.0015 & 0.0015 & 0.0011 \\
\hline & $\sigma$ & 0.0118 & 0.0147 & 0.0166 & 0.0287 & 0.0218 & 0.0117 & 0.0074 & 0.0086 & 0.0070 & 0.0160 \\
\hline \multirow{2}{*}{ SMB } & $\mu$ & -0.0010 & -0.0047 & 0.0021 & -0.0005 & 0.0036 & 0.0005 & 0.0034 & 0.0010 & -0.0002 & 0.0005 \\
\hline & $\sigma$ & 0.0124 & 0.0169 & 0.0138 & 0.0279 & 0.0136 & 0.0146 & 0.0112 & 0.0109 & 0.0082 & 0.0154 \\
\hline \multirow{2}{*}{$\begin{array}{l}\text { Market } \\
\text { volatility }\end{array}$} & $\mu$ & 0.0210 & 0.0243 & 0.0241 & 0.0308 & 0.0302 & 0.0319 & 0.0228 & 0.0190 & 0.0174 & 0.0243 \\
\hline & $\sigma$ & 0.0055 & 0.0093 & 0.0040 & 0.0074 & 0.0071 & 0.0079 & 0.0052 & 0.0037 & 0.0030 & 0.0082 \\
\hline
\end{tabular}

Observations are weekly frequency from 1997 to 2005. "Market" is the CRSP value-weighted return index, " $\Delta$ Yield" is the change of the 3-month Treasury bill, " $\Delta$ Term" is the change in the slope of the term structure (10-year less 3-month Treasury rates), " $\Delta$ Baa" and " $\Delta$ Aa" are changes in the option adjusted yield spreads for Moody's Baa- and Aa-rated corporate bonds using the Merrill Lynch indices, "HML" and "SMB" are the value and size factors obtained from Ken French’s website, and "Market Volatility” is the conditional volatility of "Market” using an EGARCH(1,1) model. 
Table 3: Average Adjusted-R² across Models, 1997-2005

\begin{tabular}{|c|c|c|c|c|c|c|c|c|c|c|}
\hline & $\underline{1997}$ & $\underline{1998}$ & 1999 & $\underline{2000}$ & $\underline{2001}$ & $\underline{2002}$ & $\underline{2003}$ & $\underline{2004}$ & $\underline{2005}$ & Average \\
\hline \multicolumn{11}{|c|}{ Panel A: All Banks } \\
\hline CAPM & 0.098 & 0.170 & 0.034 & 0.033 & 0.069 & 0.168 & 0.128 & 0.141 & 0.163 & 0.112 \\
\hline Bank-Factor & 0.101 & 0.188 & 0.048 & 0.042 & 0.064 & 0.175 & 0.129 & 0.152 & 0.152 & 0.117 \\
\hline Fama-French & 0.108 & 0.217 & 0.063 & 0.067 & 0.087 & 0.208 & 0.150 & 0.159 & 0.185 & 0.138 \\
\hline Nine-Factor & 0.107 & 0.236 & 0.089 & 0.070 & 0.086 & 0.223 & 0.153 & 0.177 & 0.191 & 0.148 \\
\hline $\mathrm{N}$ & 507 & 520 & 519 & 504 & 494 & 481 & 486 & 451 & 433 & 488.33 \\
\hline \multicolumn{11}{|c|}{ Panel B: Large Banks } \\
\hline CAPM & 0.494 & 0.512 & 0.207 & 0.123 & 0.365 & 0.651 & 0.512 & 0.304 & 0.371 & 0.393 \\
\hline Bank-Factor & 0.515 & 0.534 & 0.200 & 0.157 & 0.369 & 0.661 & 0.516 & 0.307 & 0.361 & 0.402 \\
\hline Fama-French & 0.523 & 0.545 & 0.322 & 0.359 & 0.386 & 0.668 & 0.510 & 0.335 & 0.409 & 0.451 \\
\hline Nine -Factor & 0.533 & 0.576 & 0.334 & 0.351 & 0.368 & 0.680 & 0.509 & 0.338 & 0.425 & 0.457 \\
\hline $\mathrm{N}$ & 34 & 34 & 35 & 36 & 33 & 36 & 36 & 32 & 31 & 34.11 \\
\hline
\end{tabular}

\begin{tabular}{lrrrrrrrrrr}
\hline \multicolumn{10}{c}{ Panel C: Other Banks } \\
\hline CAPM & 0.070 & 0.146 & 0.022 & 0.027 & 0.048 & 0.129 & 0.097 & 0.128 & 0.147 & 0.090 \\
Bank-Factor & 0.071 & 0.163 & 0.037 & 0.033 & 0.042 & 0.136 & 0.099 & 0.140 & 0.135 & 0.095 \\
Fama-French & 0.078 & 0.194 & 0.044 & 0.045 & 0.066 & 0.171 & 0.121 & 0.146 & 0.168 & 0.115 \\
Nine-Factor & 0.077 & 0.212 & 0.071 & 0.049 & 0.066 & 0.186 & 0.125 & 0.165 & 0.173 & 0.125 \\
$\mathrm{~N}$ & 473 & 486 & 484 & 468 & 461 & 445 & 450 & 419 & 402 & 454.22 \\
\hline
\end{tabular}

Reported values for each year are the average across the bank-specific regressions with weekly returns from 1997 to 2005. The last column show the simple average across those years; thus it is an average (over time) of averages (across banks). CAPM is the one-factor market return model in Eq. (6). BankFactor adds the short-term Treasury yield, the slope of the term structure, and a credit spread in Eq. (7). Fama-French includes market return, HML and SMB in Eq. (8). The Nine-Factor model combines all those factors and adds market volatility, the option adjusted yields for Aa corporate bonds and commercial paper (CP) spread in Eq. (9). Panel B shows the results only for the large banks, while Panel C shows the results for the other banks. A bank is considered "large" in a given year if it is part of the S\&P 500 index in that year. For a description of the factors, see Table1. 
Table 4: Summary Statistics for Factor Loadings

\begin{tabular}{|c|c|c|c|c|}
\hline & $\underline{\text { CAPM }}$ & Bank-Factor & Fama-French & Nine-Factor \\
\hline \multicolumn{5}{|c|}{ Panel A: Large Banks } \\
\hline Market & $1.0546(9 / 9 ; 0 \%)$ & $1.0804(9 / 9 ; 0 \%)$ & 1.2206 (9/9; 0\%) & $1.2520(9 / 9 ; 0 \%)$ \\
\hline$\Delta$ Yield & & $-0.0222(5 / 9 ; 60 \%)$ & & $-0.0242(2 / 9 ; 59 \%)$ \\
\hline$\Delta$ Term & & $-0.0721(5 / 9 ; 65 \%)$ & & $-0.0120(3 / 9 ; 60 \%)$ \\
\hline$\Delta$ Baa spread & & 0.0238 (5/9; 39\%) & & $-0.0024(4 / 9 ; 54 \%)$ \\
\hline$\Delta$ Aa spread & & & & 0.0104 (5/9; 47\%) \\
\hline$\Delta \mathrm{CP}$ spread & & & & $-0.0077(3 / 9 ; 49 \%)$ \\
\hline HML & & & 0.2742 (6/9; 30\%) & 0.2989 (7/9; 30\%) \\
\hline SMB & & & -0.3308 (7/9; 78\%) & $-0.2534(4 / 9 ; 69 \%)$ \\
\hline Mkt. volatility & & & & $0.4351(3 / 9 ; 37 \%)$ \\
\hline \multicolumn{5}{|c|}{ Panel B: Other Banks } \\
\hline Market & $0.4321(9 / 9 ; 14 \%)$ & $0.4375(9 / 9 ; 17 \%)$ & $0.5030(9 / 9 ; 14 \%)$ & $0.5112(9 / 9 ; 16 \%)$ \\
\hline$\Delta$ Yield & & $-0.0067(5 / 9 ; 52 \%)$ & & $-0.0069(6 / 9 ; 53 \%)$ \\
\hline$\Delta$ Term & & -0.0038 (6/9; 53\%) & & $-0.0002(3 / 9 ; 50 \%)$ \\
\hline$\Delta$ Baa spread & & 0.0176 (5/9; 48\%) & & 0.0258 (5/9; 47\%) \\
\hline$\Delta$ Aa spread & & & & $-0.0055(3 / 9 ; 50 \%)$ \\
\hline$\Delta \mathrm{CP}$ spread & & & & $-0.0101(3 / 9 ; 50 \%)$ \\
\hline HML & & & 0.2569 (9/9; 33\%) & 0.2821 (9/9; 33\%) \\
\hline SMB & & & 0.3163 (9/9; 29\%) & $0.3484(9 / 9 ; 29 \%)$ \\
\hline Mkt. volatility & & & & $0.0949(5 / 9 ; 49 \%)$ \\
\hline
\end{tabular}

\begin{tabular}{|c|c|c|c|c|}
\hline \multicolumn{5}{|c|}{ Panel C: Large vs. Other Banks } \\
\hline Market & $9 / 9$ & $9 / 9$ & $9 / 9$ & $9 / 9$ \\
\hline$\Delta$ Yield & & $4 / 9$ & & $2 / 9$ \\
\hline$\Delta$ Term & & $3 / 9$ & & $2 / 9$ \\
\hline$\Delta$ Baa spread & & $2 / 9$ & & $6 / 9$ \\
\hline$\Delta$ Aa spread & & & & $2 / 9$ \\
\hline$\Delta \mathrm{CP}$ spread & & & & $1 / 9$ \\
\hline HML & & & $4 / 9$ & $3 / 9$ \\
\hline SMB & & & $9 / 9$ & $9 / 9$ \\
\hline Mkt.Volatility & & & & $3 / 9$ \\
\hline
\end{tabular}


Table 5: Impact of a one Standard Deviation in Conditioning Variables

\begin{tabular}{|c|c|c|c|c|}
\hline & CAPM & Bank-factor & Fama-French & Nine-Factor \\
\hline \multicolumn{5}{|c|}{ Panel A: Large Banks } \\
\hline Market & 0.0250 & 0.0257 & 0.0290 & 0.0300 \\
\hline$\Delta$ Yield & & -0.0027 & & -0.0024 \\
\hline$\Delta$ Term & & -0.0023 & & -0.0017 \\
\hline$\Delta$ Baa spread & & 0.0014 & & 0.0003 \\
\hline$\Delta$ Aa spread & & & & 0.0005 \\
\hline$\Delta \mathrm{CP}$ spread & & & & -0.0001 \\
\hline HML & & & 0.0047 & 0.0050 \\
\hline SMB & & & -0.0057 & -0.0047 \\
\hline Market volatility & & & & 0.0014 \\
\hline Weekly returns: $\bar{r}(\hat{\sigma})$ & \multicolumn{4}{|c|}{$0.0030(0.0450)$} \\
\hline
\end{tabular}

\begin{tabular}{lccc}
\hline \multicolumn{4}{c}{ Panel B: Other Banks } \\
\hline Market & 0.0095 & 0.0096 & 0.0117 \\
$\Delta$ Yield & -0.0006 & 0.0119 \\
$\Delta$ Term & -0.0005 & -0.0009 \\
$\Delta$ Baa spread & 0.0003 & -0.0001 \\
$\Delta$ Aa spread & & 0.0008 \\
$\Delta$ CP spread & & -0.0002 \\
HML & & 0.0040 & -0.0005 \\
SMB & 0.0039 & 0.0043 \\
Market volatility & & 0.0043 \\
\hline Weekly returns: $\bar{r}(\hat{\sigma})$ & $0.0041(0.0430)$ & 0.0003 \\
\hline
\end{tabular}

Predicted change in weekly bank returns from a one standard deviation change in the conditioning variables, split by bank size. For example, if $\hat{\sigma}_{m, t}$ is the estimated standard deviation of the market return in year $t$, and $\hat{\beta}_{i m, t}$ is the corresponding estimated factor loading for the $i^{\text {th }}$ bank, then the impact is computed as $\frac{1}{T} \sum_{t=1}^{T}\left(\frac{1}{N_{t}} \sum_{i=1}^{N_{t}} \hat{\beta}_{i m, t} \hat{\sigma}_{m, t}\right)$, where $N_{t}$ is the number of banks in year $t$, and $T=9$ years from 1997 to 2005. A bank is considered "large" in a given year if it is part of the S\&P 500 index in that year. 
Table 6: Principal Component Analysis of Residuals

\begin{tabular}{|c|c|c|c|c|c|c|c|c|c|c|}
\hline \multirow{2}{*}{\multicolumn{2}{|c|}{ \% explained by first PC }} & $\underline{1997}$ & $\underline{1998}$ & $\underline{1999}$ & $\underline{2000}$ & $\underline{2001}$ & $\underline{2002}$ & $\underline{2003}$ & $\underline{2004}$ & $\underline{2005}$ \\
\hline & & 19.09 & 21.07 & 29.97 & 46.80 & 35.34 & 23.32 & 25.96 & 23.80 & 21.35 \\
\hline \multirow{3}{*}{$\begin{array}{l}\text { \# of PCs needed } \\
\text { to explain \% of } \\
\text { variance }\end{array}$} & $50 \%$ & 5 & 4 & 4 & 2 & 3 & 3 & 4 & 4 & 4 \\
\hline & $75 \%$ & 10 & 9 & 9 & 6 & 8 & 8 & 8 & 9 & 9 \\
\hline & $95 \%$ & 20 & 20 & 21 & 16 & 18 & 19 & 19 & 19 & 18 \\
\hline \multicolumn{2}{|c|}{$\begin{array}{l}\text { \# of negative factor } \\
\text { loadings for first PC / } \\
\text { max possible }\end{array}$} & $1 / 34$ & $30 / 34$ & $0 / 35$ & $36 / 36$ & 0/33 & 3/36 & 28/36 & $5 / 32$ & $30 / 31$ \\
\hline \multicolumn{2}{|l|}{ N (weeks) } & 52 & 52 & 52 & 39 & 52 & 52 & 53 & 52 & 52 \\
\hline
\end{tabular}

Principal component analysis for the residuals from the the Nine-Factor model for large banks from 1997 to 2005. The maximum number of negative factor loadings on the first PC varies by year with the number of banks represented in the S\&P 500 index varies every year. 
Table 7: Results for Large Firms from all S\&P Sectors

\begin{tabular}{|c|c|c|c|c|c|c|c|c|c|}
\hline \multirow{3}{*}{ S\&P 500 Sectors } & \multirow{3}{*}{$\begin{array}{l}\text { Avg. \# } \\
\text { of Firms } \\
\text { (1) }\end{array}$} & \multirow[b]{2}{*}{$\begin{array}{c}\text { Avg. } \overline{\mathrm{R}}^{2} \\
\text { (Nine-Factor) }\end{array}$} & \multirow{3}{*}{$\begin{array}{c}\text { Percent } \\
\text { Explained } \\
\text { by First PC } \\
\text { (3) }\end{array}$} & \multirow{3}{*}{$\begin{array}{c}\text { Factor } \\
\text { Loading } \\
\text { Agreement } \\
\text { on First PC } \\
\text { (4) }\end{array}$} & \multicolumn{3}{|c|}{$\underline{\text { Unweighted Correlation }}$} & \multicolumn{2}{|c|}{$\underline{\text { Reduction in Correlation }}$} \\
\hline & & & & & Returns & $\begin{array}{l}\text { Fama- } \\
\text { French }\end{array}$ & $\begin{array}{l}\text { Nine- } \\
\text { Factor }\end{array}$ & $\begin{array}{c}\text { Returns to } \\
\text { Fama-French } \\
\text { Residuals }\end{array}$ & $\begin{array}{c}\text { Fama-French } \\
\text { Residuals to } \\
\text { Nine-Factor } \\
\text { Residuals }\end{array}$ \\
\hline & & $(2)$ & & & (5) & (6) & (7) & (8) & (9) \\
\hline Energy & 25.8 & 0.25 & $52 \%$ & $98 \%$ & 0.565 & 0.427 & 0.428 & $24 \%$ & $0 \%$ \\
\hline Industrials & 65.8 & 0.32 & $16 \%$ & $74 \%$ & 0.333 & 0.069 & 0.067 & $79 \%$ & $3 \%$ \\
\hline Consumer Discretionary & 87.9 & 0.28 & $14 \%$ & $80 \%$ & 0.300 & 0.067 & 0.065 & $78 \%$ & $2 \%$ \\
\hline Consumer Staples & 38.2 & 0.17 & $18 \%$ & $85 \%$ & 0.251 & 0.116 & 0.118 & $54 \%$ & $-2 \%$ \\
\hline Health Care & 43.3 & 0.19 & $17 \%$ & $81 \%$ & 0.241 & 0.102 & 0.103 & $58 \%$ & $-1 \%$ \\
\hline Financials & 40.0 & 0.41 & $21 \%$ & $79 \%$ & 0.437 & 0.120 & 0.116 & $72 \%$ & $4 \%$ \\
\hline Telecomm Services & 11.7 & 0.25 & $34 \%$ & $84 \%$ & 0.356 & 0.188 & 0.183 & $47 \%$ & $3 \%$ \\
\hline Utilities & 36.4 & 0.28 & $30 \%$ & $90 \%$ & 0.447 & 0.290 & 0.272 & $35 \%$ & $6 \%$ \\
\hline BANKS & 34.1 & 0.46 & $27 \%$ & $93 \%$ & 0.573 & 0.244 & 0.236 & $57 \%$ & $3 \%$ \\
\hline Median & 40.0 & 0.28 & $21 \%$ & $84 \%$ & 0.36 & 0.12 & 0.12 & $57 \%$ & $2 \%$ \\
\hline
\end{tabular}

Results are for all large firm regressions for all S\&P sectors. All results are averages across annual observations for the nine year sample from 1997 to 2005. Average $\overline{\mathrm{R}}^{2}$ is the mean from the Nine-Factor model. \% Explained by the first PC is the percent of total variation explained by the first principal component of the Nine-Factor model residuals. Factor loading agreement on 1st PC is the percent of firms with a factor loading of the same sign. Unweighted correlations are the mean pair-wise correlations of returns or market model residuals in each year. \% Reduction in Correlation is the percentage decline in the mean pair-wise correlation from the returns to the Fama-French residuals (column 8) or from Fama-French residuals to NineFactor model residuals (column 9). 
Figure 1: Average Adjusted-R ${ }^{2}$ over Years and Bank Size

Large Banks

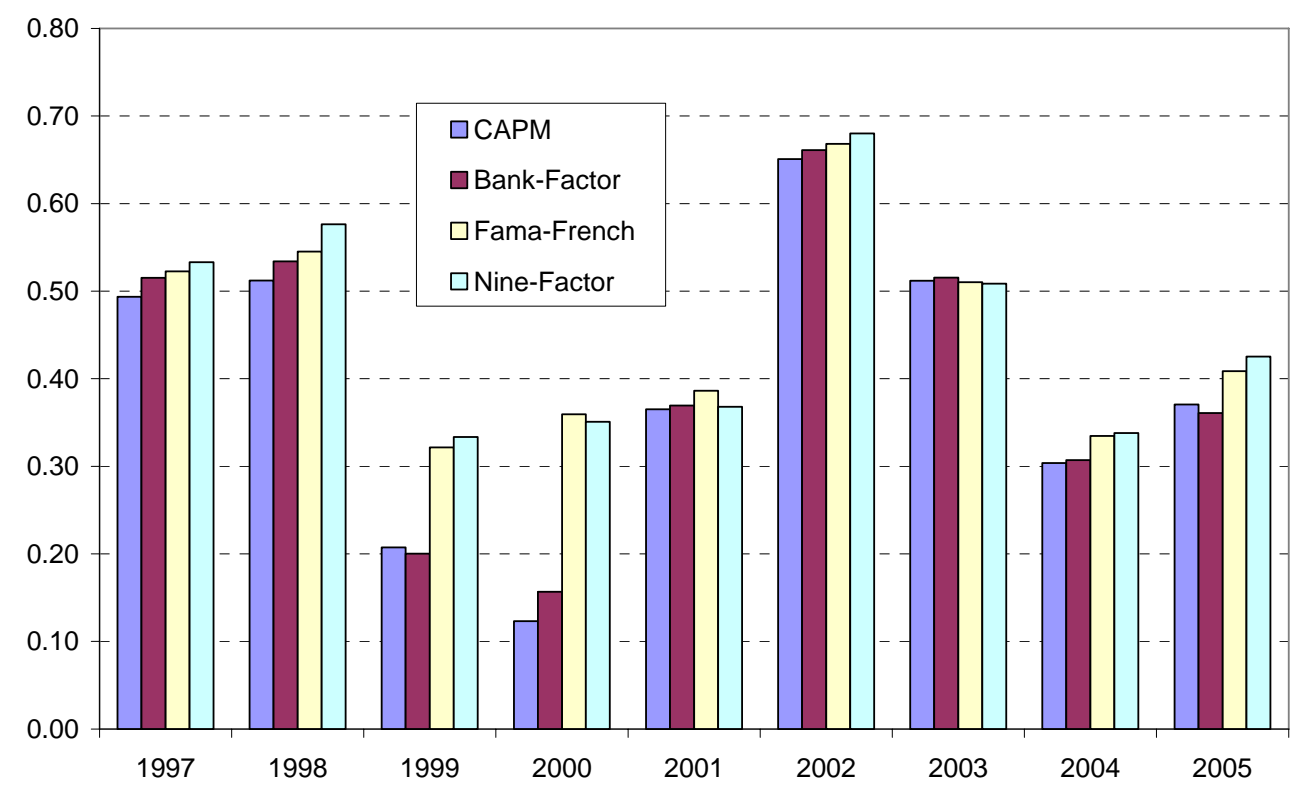

Other Banks

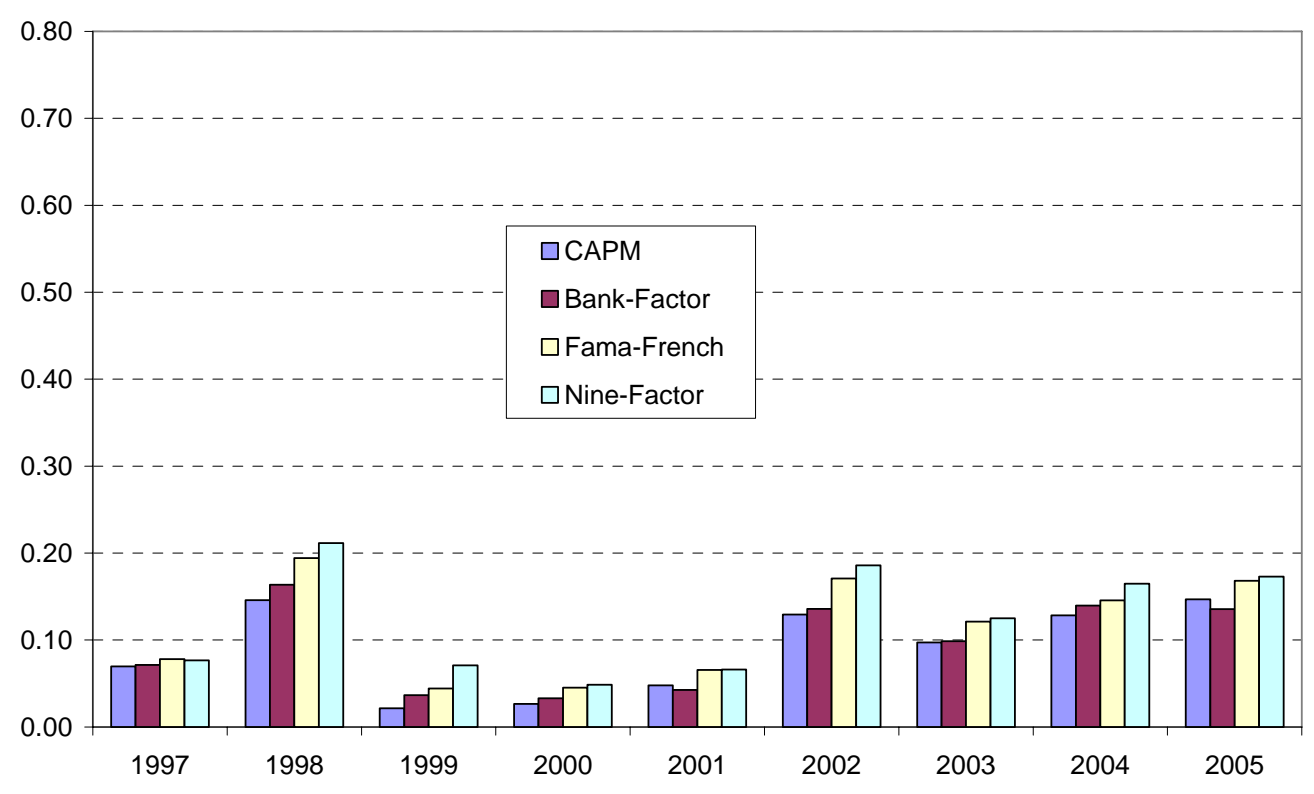

Average adjusted- $\mathrm{R}^{2}$ is the average across the bank-specific regressions of weekly returns in each year from 1997 to 2005. CAPM is the one-factor market return model, given by Eq. (6), Bank-Factor adds the short-term Treasury yield, the slope of the term structure, and a credit spread, Eq. (7), Fama-French is the three factor model of market return, HML and SMB, Eq. (8), while Nine-Factor combines all those factors and adds market volatility, Aa spread and liquidity, Eq. (9). Top Panel takes the large banks, while the bottom panel shows all other banks. A bank is considered "large" in a given year if it is part of the S\&P 500 index in that year. 
Figure 2: Average Correlations of Returns and Residuals by Year and Bank Size
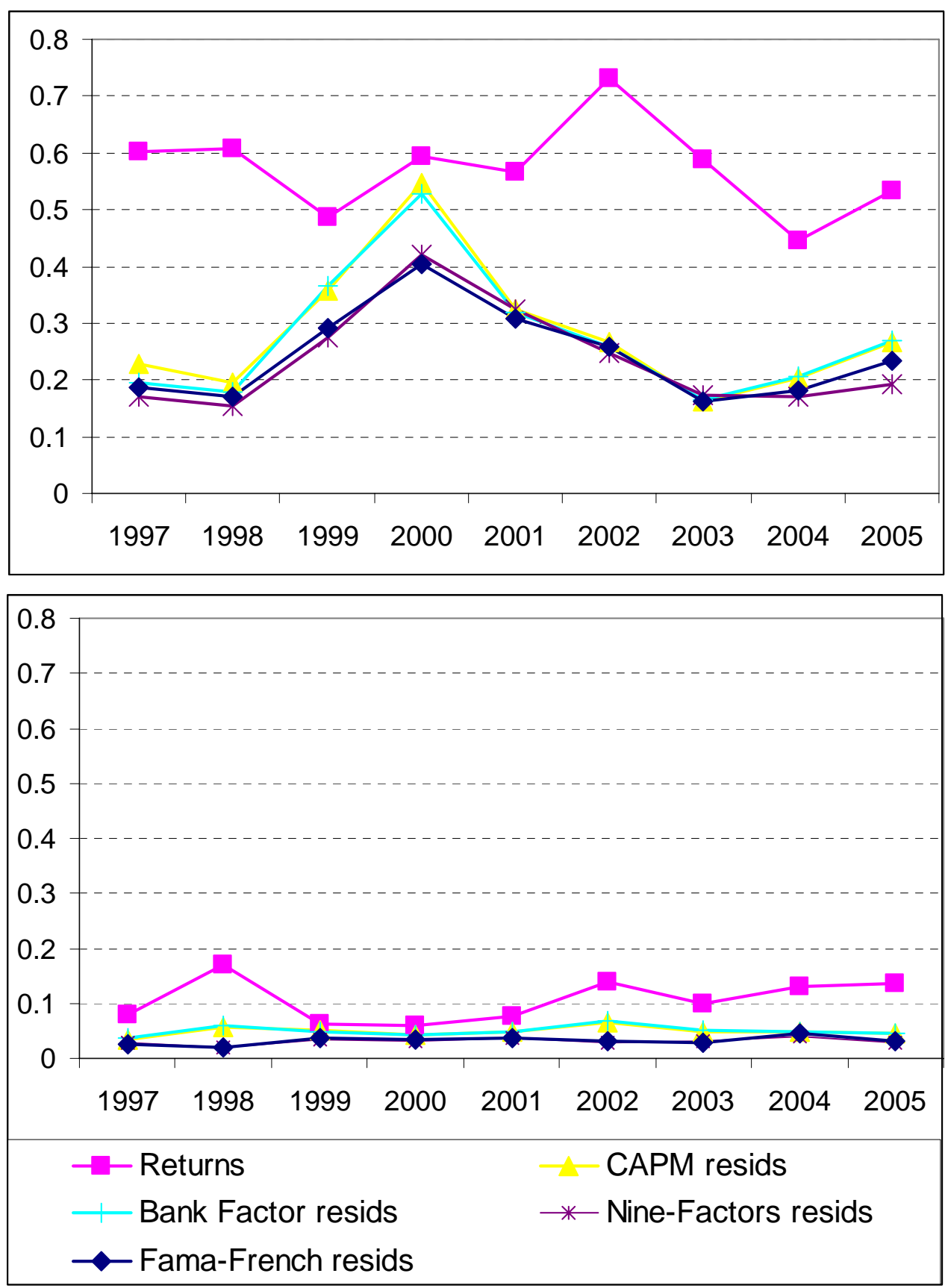

Each year observation is the mean pair-wise corelation for all institutions. The top panel is the unweighted average across largest banks, while the bottom panel is the unweighted average across the other banks. A bank is considered "large" in a given year if it is part of the S\&P 500 index in that year. 
Figure 3: Average Adjusted-R ${ }^{2}$ across Sectors, 1997-2005

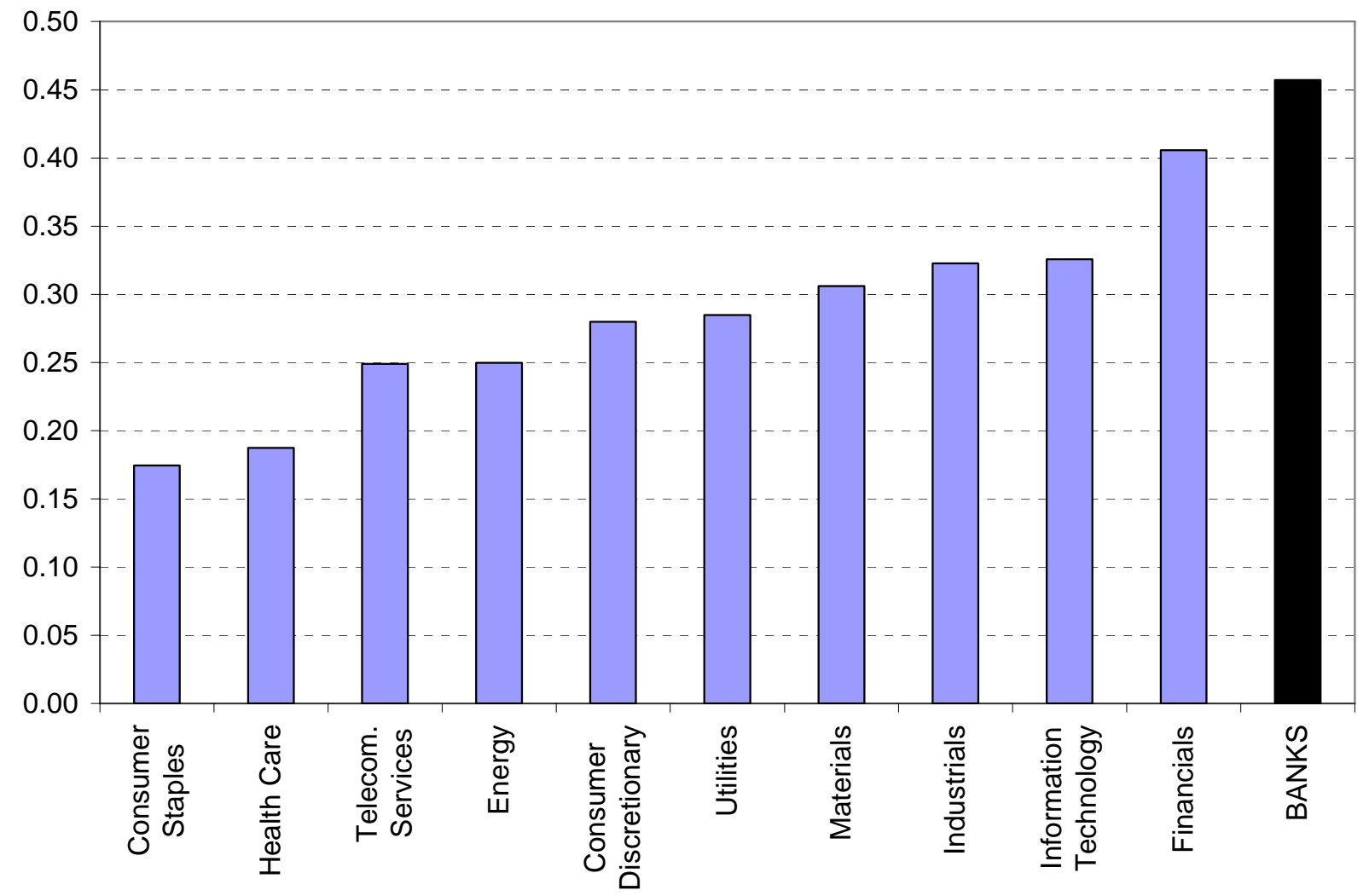

Average adjusted- $\mathrm{R}^{2}$ is from the Nine-Factor model in Eq. (9). Each bar is the average (across years) of the average (across firms) for each sector. All firm are included in the S\&P500 in a given year. 